\title{
Article \\ Advances in Multi-Process Hybrid Production Cells for Rapid Individualised Laser-Based Production
}

\author{
Juan Carlos Pereira ${ }^{1, *(\mathbb{D})}$, Ramón Moreno ${ }^{1}\left(\mathbb{D}\right.$, Christian Tenbrock $^{2} \mathbb{D}$, Arnold Herget ${ }^{3}$, Thomas Wittich ${ }^{4}$ and \\ Kelvin Hamilton 5
}

check for updates

Citation: Pereira, J.C.; Moreno, R.; Tenbrock, C.; Herget, A.; Wittich, T.; Hamilton, K. Advances in Multi-Process Hybrid Production Cells for Rapid Individualised Laser-Based Production. Appl. Sci. 2021, 11, 1812. https://doi.org/ 10.3390/app11041812

Academic Editor: Saulius Juodkazis Received: 16 January 2021

Accepted: 12 February 2021

Published: 18 February 2021

Publisher's Note: MDPI stays neutral with regard to jurisdictional claims in published maps and institutional affiliations.

Copyright: (c) 2021 by the authors. Licensee MDPI, Basel, Switzerland. This article is an open access article distributed under the terms and conditions of the Creative Commons Attribution (CC BY) license (https:// creativecommons.org/licenses/by/ $4.0 /)$.
1 LORTEK Technological Centre, Basque Research and Technology Alliance (BRTA), Arranomendia Kalea 4A, 20240 Ordizia, Spain; rmoreno@lortek.es

2 Fraunhofer ILT-Institute for Laser Technology, Steinbachstraße 15, 52074 Aachen, Germany; christian.tenbrock@ilt.fraunhofer.de

3 SmartFactory-KL, Trippstadter Str. 122, 67663 Kaiserslautern, Germany; Arnold.Herget@smartfactory.de

4 EROWA AG, Knutwilerstrasse 3, 6233 Büron, Switzerland; thomas.wittich@erowa.com

5 AUTODESK Ltd, Small Heath Business Park, Talbot Way, Birmingham B10 0HJ, UK; kelvin.hamilton@autodesk.com

* Correspondence: jcpereira@lortek.es; Tel.: +34-943-88-23-03

\begin{abstract}
In this paper, the approach and main advances made in multi-process hybrid production cells (HyProCell) for rapid individualised laser-based production are compiled and discussed, including highlights and achievements. HyProCell constructs automated manufacturing platforms that integrate highly flexible laser-based additive build processes with more conventional yet precise subtractive machining processes and include novel solutions like automatic powder removal system/machines and robot arms in integrated multi-process production cells. The HyProCell approach can either build parts additively from scratch and finish them in a coherent production single line/cell or prepare parts by machining and add laser-based additive features, achieving otherwise impossible shapes. In addition to producing new parts, existing parts can be repaired or improved by adding new details with the HyProCell hybrid concept. The research work includes the design of pilot cell facilities, the development of the, and a new modular architecture including a middleware and integration layer to ensure automation with improved pallet handling systems. Finally, the MES and data management methodologies for future improvements and pilot facility implementation were made.
\end{abstract}

Keywords: hybrid additive manufacturing; laser-based production; manufacturing digitization; automated multiprocess production cell

\section{Introduction}

Individualised production is the manufacturing of products or lots of parts that are uniquely differentiated from one another. It is an emerging trend which provides added value and distinction within high-value manufacturing: suppliers can provide more ad hoc competitive products (according to the customer's wishes) and deliver new services and localised functionalities (production on demand).

Laser-based additive manufacturing (LBAM) [1] is well suited to individualised on-demand production due to its ability to transform digital designs directly into physicalcomplex products, particularly for small batch sizes. In recent years, metallic additive manufacturing (AM) has generated great industrial interest in different sectors [2] and has grown significantly, and hybrid AM (alternating additive material deposition and subtractive material removal) opens new possibilities in terms of flexibility and productivity in the automated production of net parts of high complexity and low cost [3]. The metal machine AM market is witnessing an emerging and critical time [4], but it is not yet competitive on a large scale, especially because additively manufactured parts are often more expensive 
than those produced by conventional methods, and production speed is not as fast as promised [5]. Aside from the manufacturing time inherent in layer-by-layer material-laser interaction using additive processes, significant downtime is involved in the adjustment of machines from one batch to another, such as in the changing of materials, cooling of the part, preparation and extraction of the manufacturing platform, final extraction of powder in the part, etc. Additionally, the handling of parts still requires intervention by operators and other isolated processes. On the other hand, parts almost always require post-processing treatments to meet customer requirements: machining operations or surface treatments are required to meet surface quality specifications (irregular surface roughness, high requirements for the application, e.g., $<1 \mu \mathrm{m}$ for parts subjected to fatigue) and dimensions in critical areas (areas with strong dependence on tolerance, mating surfaces), or part removal from the base plate is necessary and the supports must be eliminated from the part.

This insight has motivated research into hybrid AM, a novel production approach combining additive manufacturing with other technologies [6]. This combination process is used to overcome the drawbacks of slow additive production processes by retaining the advantage of producing free-form parts without the need for moulds and forms. Some authors go in depth with new concepts for hybrid AM, combining not only subtractive and additive processes, but also the integration of assembly, forming, and measuring in an abstract concept called incremental manufacturing, which comprises robot-based and thus geometrically flexible step-by-step additive finalisation of prefabricated basic parts with a high build-up rate and, if needed, subsequent subtractive finishing of functional surfaces [7].

Additionally, there is improper integration of these post-processing and other conventional processes-subtractive as well as complementary (powder removal, heat treatment, surface finishing) - with LBAM (including part design and production planning), complicating product and process traceability. On the other hand, in LBAM related facilities, different workshops in the value chain use different software to optimise the manufacturing process, and each one "thinks" about its own process as an isolated manufacturing step, even when working in the same value chain.

The HyProCell project (http:/ / www.hyprocell-project.eu/ (accessed on 16 January 2021)) proposes the combination of available cutting-edge LBAM machines and information and communication technology (ICT) innovations within an integrated multi-process production cell, which includes LBAM-specifically, selective laser melting (SLM) [8] and laser metal deposition (LMD) [9] additive processes-as well as automatic powder removal and subtractive machines, in order to ensure a fully finished product from incoming raw materials. The general objective of HyProCell is to implement and validate this concept in real manufacturing settings, manufacturing real parts and measuring the benefits and impact on production.

A conceptual overview of HyProCell (Figure 1) shows how raw materials may be processed to manufacture products. Part geometry, toolpaths and laser scanning patterns are generated by CAx tools. Autonomous and cost-effective system operation is achieved by connecting the various machines performing the manufacturing processes over a communications network that runs a manufacturing execution system (MES). The MES both triggers and controls the various manufacturing processes. Manufactured parts are transferred between machines by robotic systems using specialised clamping systems, and quality inspection is carried out across the different manufacturing phases. The concept has been validated in industrial pilot facilities by manufacturing parts to meet precise end-user requirements. Initially, manufactured parts address the aerospace, energy, and industrial equipment sectors. 


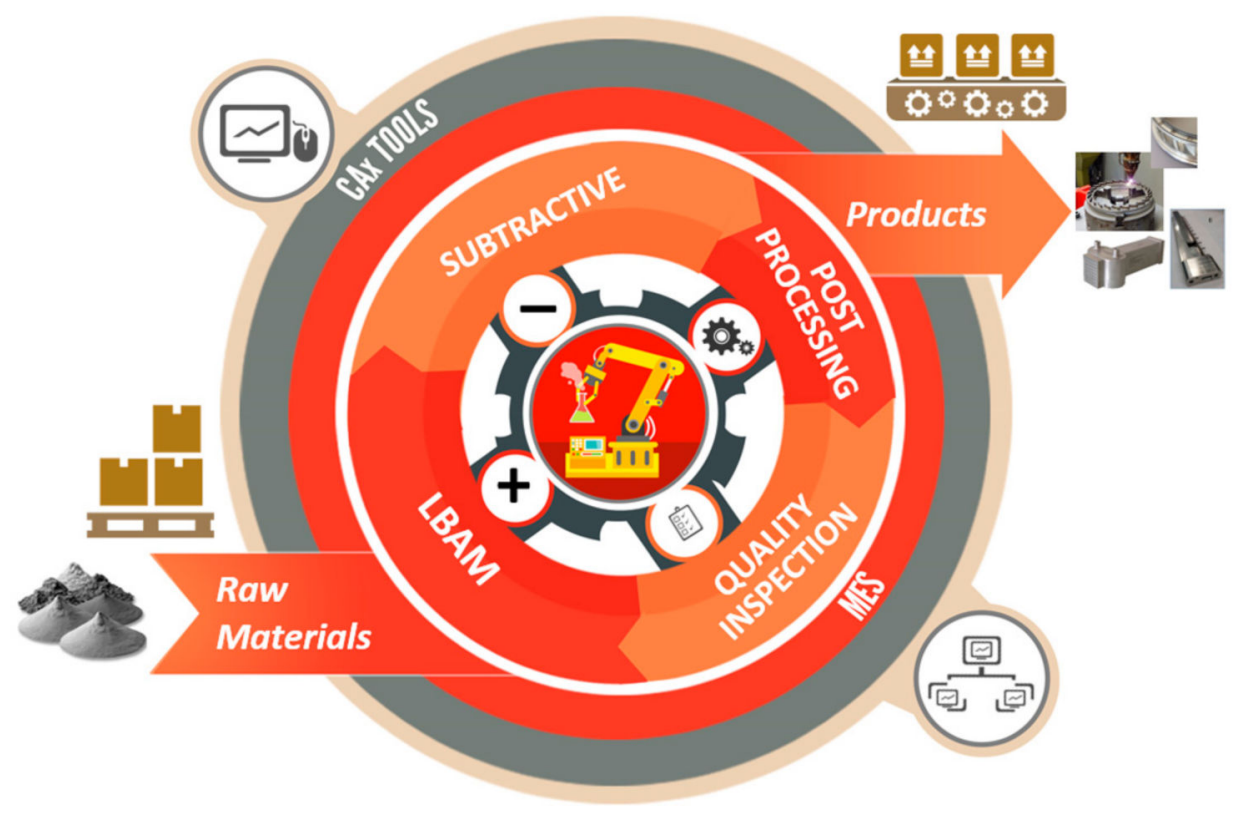

Figure 1. Conceptual overview of HyProCell.

Within the project, several key results were obtained:

(i) Development of software and toolboxes to generate modelling and manufacturing data for hybrid AM workflow

(ii) Development of a modular architecture with unified adapters (OPC-UA) for the machines

(iii) Development of middleware components for modularity and interrelation between machines and robots

(iv) Provision of suitable robotic arms and design of robust pallets and fixturing systems capable of storing and handling large and heavy parts in an inert chamber

(v) Addition of external controls to the ADIRA AC AddCreator (https:/ / adira.pt/en/ product/additive-manufacturing-2/ (accessed on 16 January 2021)) machine to make it operational as a connected module of an integrated production process, notably the addition of the automatic robot access door, new sealing elements and an automatic vacuum powder removal system for the powder remaining in the chamber after manufacturing the part

(vi) Integration of the remaining powder extraction process (inside the part), incorporating an automatic SOLUKON machine (https:/ / www.solukon.de/en/metall/sfm-at800/ (accessed on 16 January 2021)) for powder extraction in the cell

(vii) Adaptation of the HAMUEL LMD hybrid (https://hamuel.de/en/products/5-axismachining-center-hstm (accessed on 16 January 2021))machine for use under the HyProCell approach, achieving superior on-line measurement and control capabilities for the manufacturing of nozzle rings (with blades) and turbine Blisks for the turbomachinery sector

(viii) Development of an integrated manufacturing execution system (MES) that acts as an information dispatcher between the integration layer and other system components

(ix) And finally, the development of a method called splitting, clustering, graph-making (SCG) for data analysis and mining using time series processing of data acquired from SLM machines

The ultimate goal of HyProCell was to establish how these new types of automated additive AM cells can enable efficient, flexible, and high-throughput production of small lots. 


\section{HyProCell Implementation}

The full specifications and setup of the pilot facilities were developed by LORTEK considering the use cases defined covering four different sectors: aeronautic, turbomachinery, energy, and industrial equipment (use cases are not shown in this paper for commercial confidentiality reasons). The needs of end-users (POLY-SHAPE (https:/ /www.polyshape.com/ (accessed on 16 January 2021)), RAMEM (https://ramem.com/ (accessed on 16 January 2021)) and ABB Turbomachinery) (https://new.abb.com/turbocharging (accessed on 16 January 2021)) and the capabilities of technology providers within the consortium were analysed. Two pilot facilities were designed and installed: one (LMD pilot) was located in a closed production cell in the AUTODESK Technology Centre (https:/ / www.autodesk.com/technology-centers/birmingham-uk (accessed on 16 January 2021)) (Birmingham, UK), while the different processes of the second (SLM and post-processing) were distributed across two locations. Despite being separated physically, these two cells are virtually treated as a closed cell. This concept would allow testing different possible configurations of hybrid production cells. The division of the SLM pilot into sub-pilots is in location only, since the MES manages both locations from a common interface, sharing the information and ensuring traceability. Therefore, conceptually, there is only one SLM pilot line, despite being located in different partners' facilities. The sub-pilot based in POLY-SHAPE (Marseille, France) is aimed at the automation of processes linked to Additive Manufacturing of Tiled Laser Melting machines (similar principle to SLM), and the sub-pilot based in RAMEM (Torrejon de Ardoz, Spain) is aimed at the automation of dedicated post-processing of parts with demanding geometry/surface requirements and complex geometries.

\subsection{Pilot Facilities Setup}

The final setup for the pilot cells is shown in the following figures. The core component of the LMD pilot is the HSTM 150 HD hybrid machine (HAMUEL, Meeder, Germany) whose main elements are shown in Figure 2. Full automation is not required as this is a closed cell, so only the mounting device for the pallet system was designed and manufactured by EROWA (https: / / www.erowa.com/ en (accessed on 16 January 2021)), and a laser line scanning sensor has been integrated into the HAMUEL machine as well. The data flow between the CNC controller, the scanner and the scan software were developed by BCT (https: / /bct-online.de/ (accessed on 16 January 2021)).

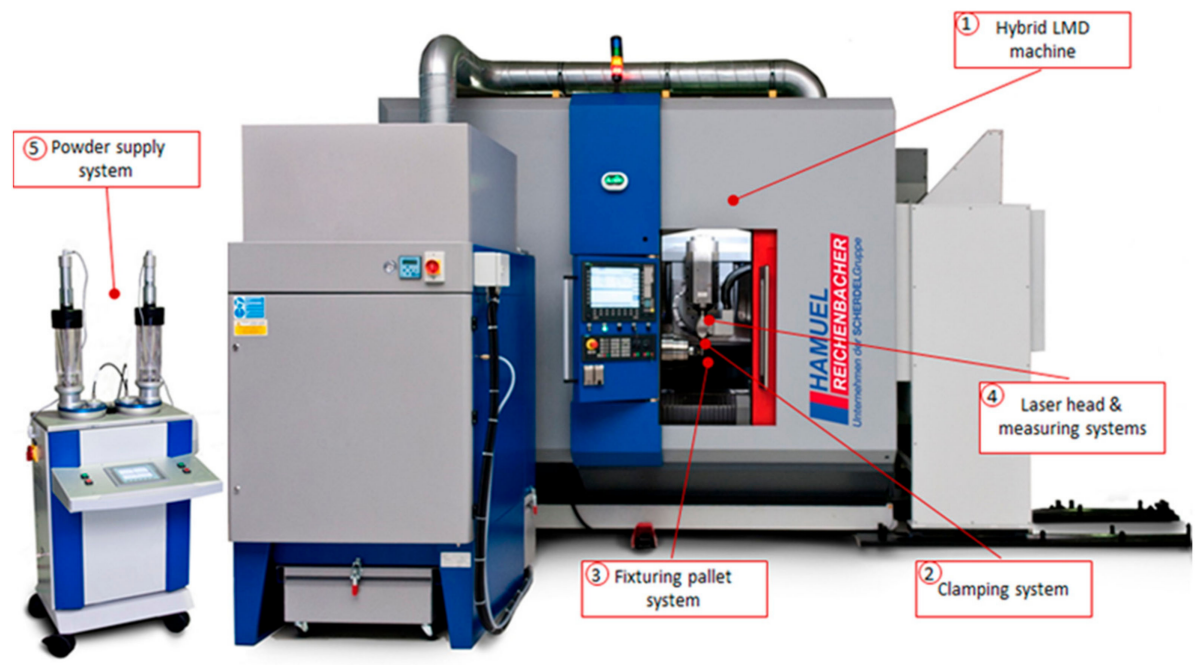

Figure 2. LMD pilot cell at AUTODESK Technology Centre in Birmingham, England. (1) Hybrid machine (HAMUEL HSTM 150 HD), (2) Clamping system (EROWA PC210), (3) Fixturing pallet system (EROWA), (4) Laser head and measuring systems, (5) Powder feeder (GTV). 
In the case of SLM pilot cells, the main interest and challenge of pilot facility design was to keep different product requirements in line by managing the interactions between partners as "module providers". This task informed other technical features (middleware, machine adaptations, and the MES) by highlighting the interfaces in the context of the cells. The nature of the SLM process-and, particularly, in the tiled laser melting (TLM) technology used in the AC AddCreator machine (ADIRA, Rua das Lages 67. 4410-272 V. N. Gaia. Portugal) a core component of the cell-requires that parts be cleaned of powder before any further post-processing steps. This requirement was fulfilled at different levels. The first level concerns the physical machine:

$>$ The use of the ADIRA TLM machine itself, which contains a primary powder removal device utilizing an automated vacuum cleaner attached to the processing head.

$>$ The use of an automated powder removal machine (SOLUKON) to perform thorough powder removal from the part, with a CNC programme specifically designed for each part.

$>$ The use of a dust box designed by EROWA for its robot, which interfaces with the ADIRA and SOLUKON machines to ensure no powder is spilled during transportation to promote safety and security of personnel and goods.

$>$ The use of the MES to ensure that every necessary step is followed.

On the second level, the design of specific pallets to ensure functionality:

$>$ The $400 \times 500 \mathrm{~mm}^{2}$ maximum size was set by the capacity of the smallest chamber: the $\mathrm{CNC}$ milling machine. The need to machine distorted build plates after AM led the team to design a system with substrate plates screwed on top of the pallet, which, in turn, provides the interface with a positioning system and the robot gripper.

$>$ The dimensions of the ADIRA machine, combined with the weight of a $400 \times 500 \mathrm{~mm}^{2}$ quench and tempered steel plate with a part built on it, compelled EROWA to design a special telescopic axis to handle a $300 \mathrm{~kg}$ payload and a dedicated clamping system with extremely high precision $(2 \mu \mathrm{m})$ when deployed and clamped.

> An adaptable sealing element was designed to adapt such a plate to the ADIRA machine, initially planned for a $1000 \times 1000 \mathrm{~mm}^{2}$ plate. The main goal behind this development was to limit the amount of powder that could contaminate the system: less powder to spread, less powder emitted during processing, less powder to clean.

$>$ The pallet was designed to adapt to different type of plates so that the cell could be used to process different plates coming from various machines.

Workflow on the MES combined with design templates for CAM tools permits the production of several parts on a single pallet.

$>$ The number of plates and the size of the magazine were scaled to allow different operations to happen simultaneously: building a part in the SLM machine, removing powder from a second newly built part, machining a plate from an external SLM machine, etc.

Finally, the cell (layout in Figure 3) was designed to fulfill these "internal" requirements as well as requirements imposed by the environment (space, utilities, and so on). The sizes of the modules and the space between them required for maintenance and operation would have resulted in a cell length of nearly $20 \mathrm{~m}$. Given the lack of space and difficulties of integration versus low added value, the 3D scan station was left physically outside the cell. However, its outputs were still virtually integrated in product information through an RFID station, the MES workflow, and the CAM tools. 


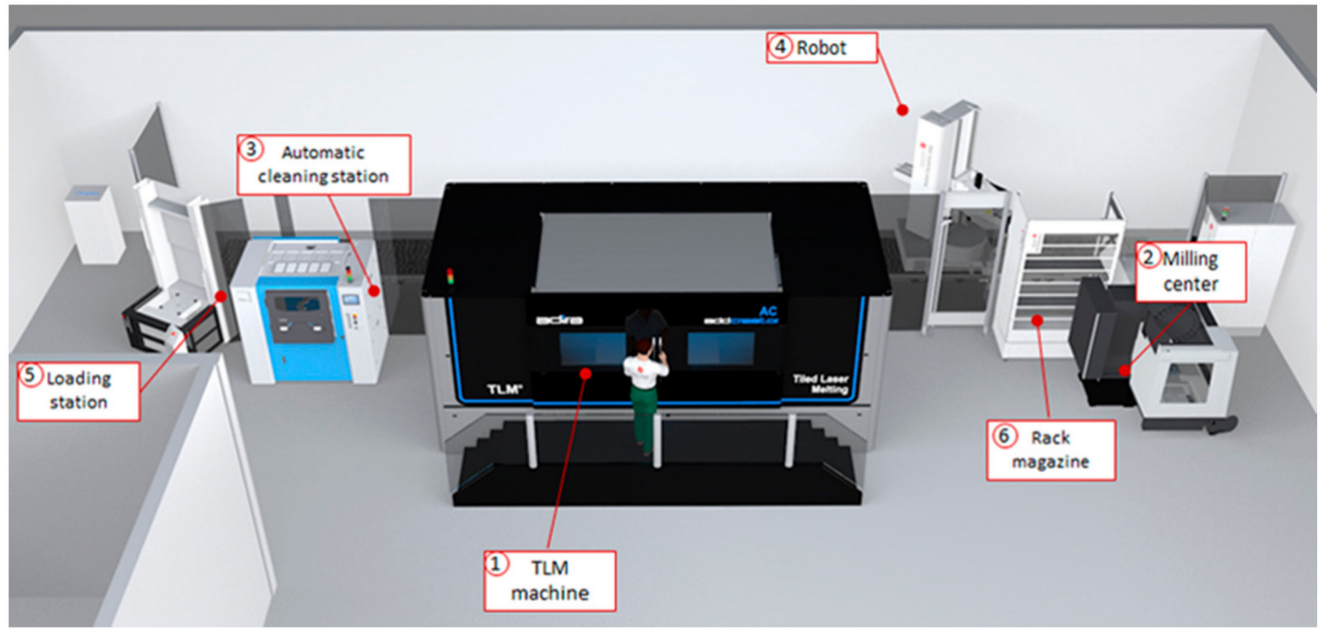

Figure 3. 3D layout of the POLY-SHAPE pilot cell overview. (1) TLM machine (ADIRA TLM AddCreator), (2) Milling centre (Haas 3-axis VF-2), (3) Cleaning station (SOLUKON AT800), (4) Robot (EROWA ERD 500), (5) Loading station (EROWA ERD 500), (6) Rack magazine (EROWA ERD 500).

In the case of the SLM post-processing cell, the final layout is shown in Figure 4.

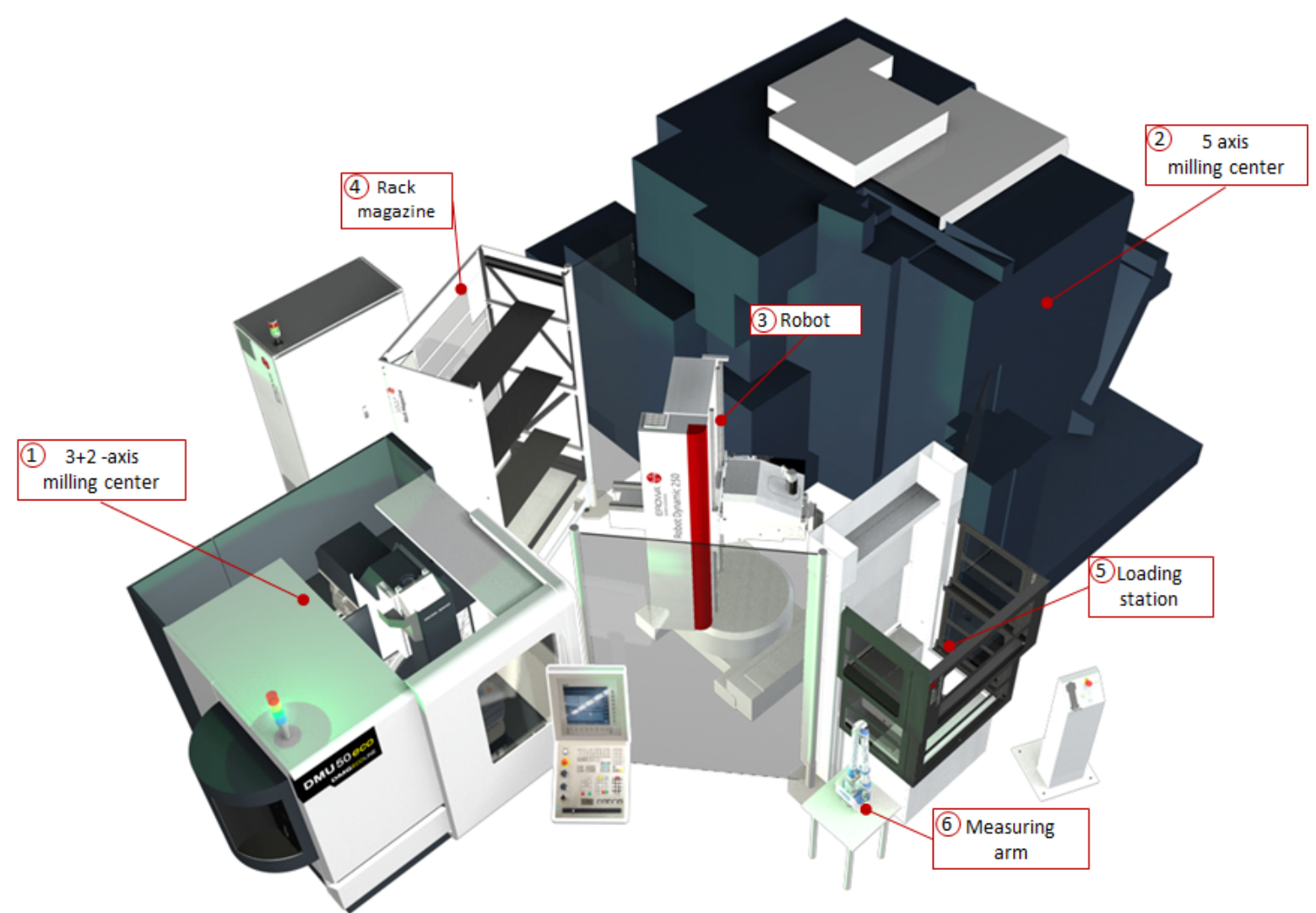

Figure 4. 3D layout of the RAMEM post-processing pilot cell overview. (1) 3 + 2-axis Milling centre (DMU 50 ECO), (2) 5-axis Milling centre (Makino DS500), (3) Robot (EROWA ERD 250 XT), (4) Rack magazine (EROWA), (5) Loading station (EROWA), (6) Measuring arm (FARO Quantum) 


\subsection{Modular Architecture, Automation, and Pallet Handling System}

Modular architecture is considered a pillar of flexible production cells in today's digital age [10]. In HyProCell, a highly modular factory architecture was developed and implemented, which allows:

(i) High interoperability between various manufacturing modules/processes/technologies

(ii) Quick and easy reconfiguration of the production cell

(iii) Scalable production infrastructure that is adaptable to other situations and demands. This modular architecture using OPC-UA adapters is required to connect the machines and the integration layer with CAx, MES and monitoring system.

The implementation and testing of the modular system architecture for generic hybrid production cells in an industrial environment was done by SmartFactory KL (https:/ / smartfactory.de/ (accessed on 16 January 2021)) within the project, and the work was published by Pahlevannejad et al. [11] based on results obtained in HyProCell. In Figure 5 the final scheme of SLM sub-pilots in POLY-SHAPE and RAMEM in terms of the middleware (integration layer) and monitoring/reconfiguration layer is shown. The LMD pilot facility at AUTODESK focuses more on the Hybrid LBAM process and the CAx integration and does not need as much automation as SLM pilots, as the whole hybrid manufacturing process could run in one closed machine with a special mounting device and 3D scanning system specific for the ABB use case. The layout of the LMD pilot is shown in Figure 6.

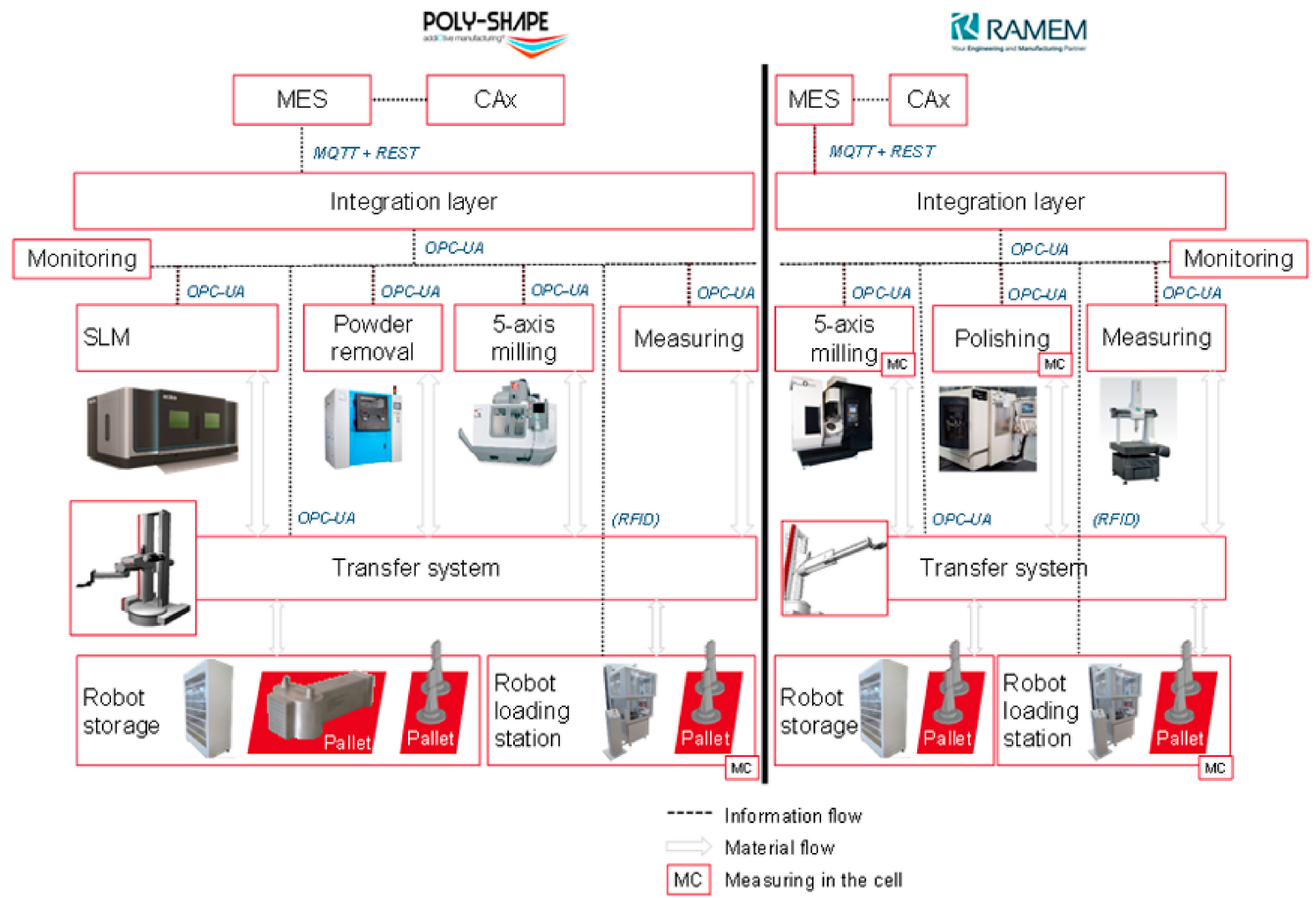

Figure 5. Layout and information of material flow of the SLM production cells [11]. Copyright 2018/2019 SmartFactory-KL (collaborative work). 


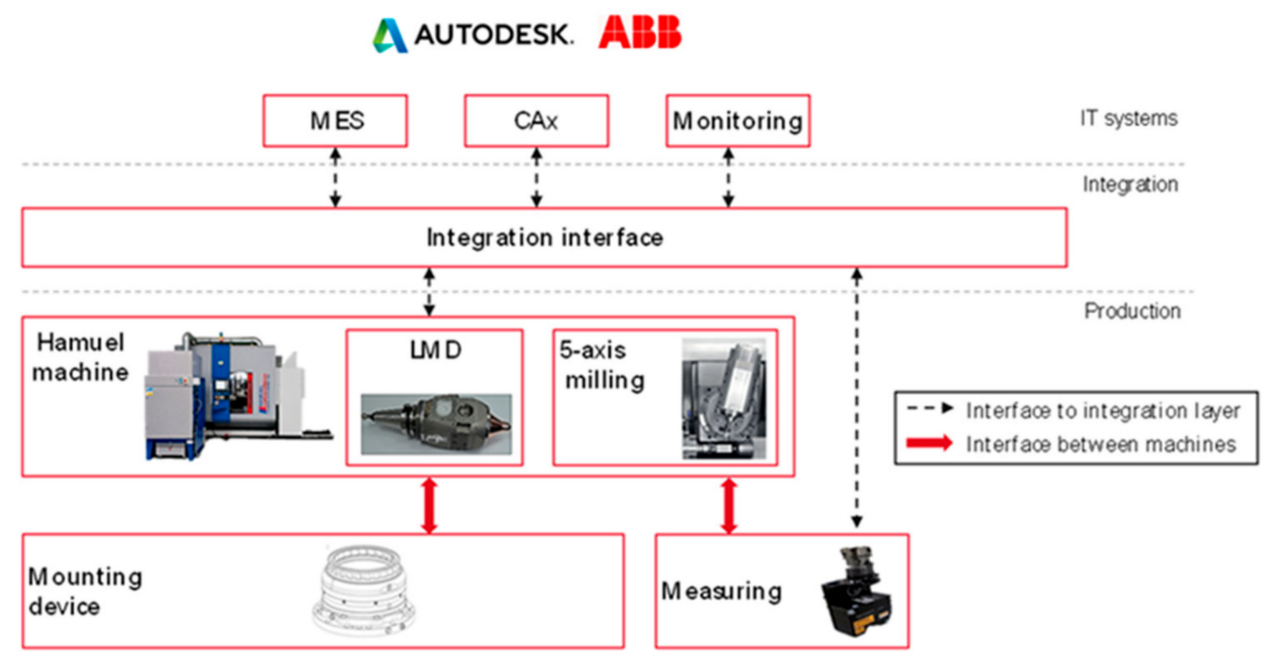

Figure 6. Layout of the LMD hybrid production cell.

The basis for development was the main high-level requirements for the HyProCell MES and the integration of the MES within the architecture to derive the design of the MES's internal architecture, with the identification of the main needed functional components particular to the industrial AM pilot cells. SmartFactory-KL developed the OPC-UA adapters and middleware components that enable data acquisition and process control for both additive and conventional manufacturing machines in the context of a reconfigurable and standardised system architecture (see simplified diagram in Figure 7). Using this architecture not only modularised production, but also decoupled the engineering processes such that each cell could be developed independently and later encapsulated within a functioning cell.

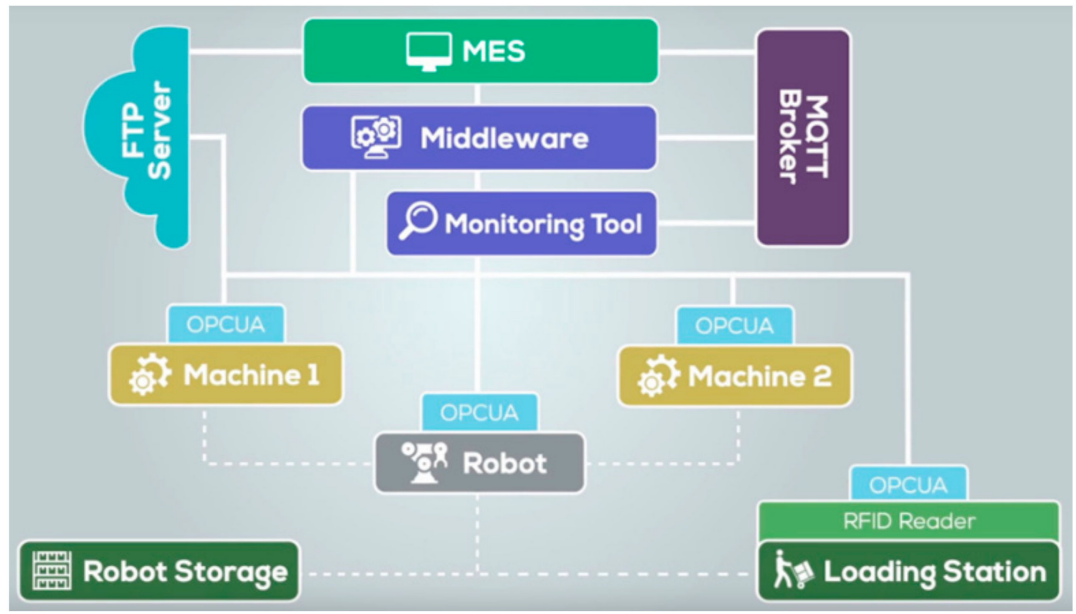

Figure 7. Simplified diagram of the HyProCell modular architecture (http:/ / www.hyprocell-project. eu/project/innovation-highlights/ (accessed on 16 January 2021)) developed by SmartFactoryKL [12]. Copyright 2019 Parsha Pahlevannejad (Smartfactory-KL).

In terms of automation and pallet handling system, the modules implemented on the AC AddCreator system for operating in a production environment are described in this section. Machine adaptations were performed by ADIRA in collaboration with EROWA. Process development and studies were conducted with the support of the Fraunhofer ILT institute.

The pallet handling system designed and adopted for HyProCell has the following novel characteristics: 
(i) A long travel arm to access the inside of the ADIRA machine combined with a high potential transfer weight of over $300 \mathrm{~kg}$, which required a new high-accuracy $(2 \mu \mathrm{m})$ robot arm design;

(ii) A new fork gripper and special pallet design to deal with the impact of the powder on the robot gripper system;

(iii) Sealing the pallet to the machine table inside the ADIRA machine, which was solved with a special chuck base plate and fitted sealing;

(iv) The transfer of the pallet from the ADIRA machine to the SOLUKON powder removal system without leaving an unacceptable amount of powder in the environment. To prevent this, a special box on the robot with the sealing concept was chosen and designed to keep falling powder inside a controlled area;

(v) Finally, the modular communication interface was extended with an appropriate concept to maintain modularity and keep the system safe.

In order to access the machine working area with the external handling system, a suitable robot access door was created. This module took into account the requirements of the EROWA dust box system and handling robot arm to guarantee safe handling of the substrate plate, finished part, and possible remaining powder while always maintaining control over the atmosphere around the part. The final dust box used on the handling robot arm is shown in Figure 8.
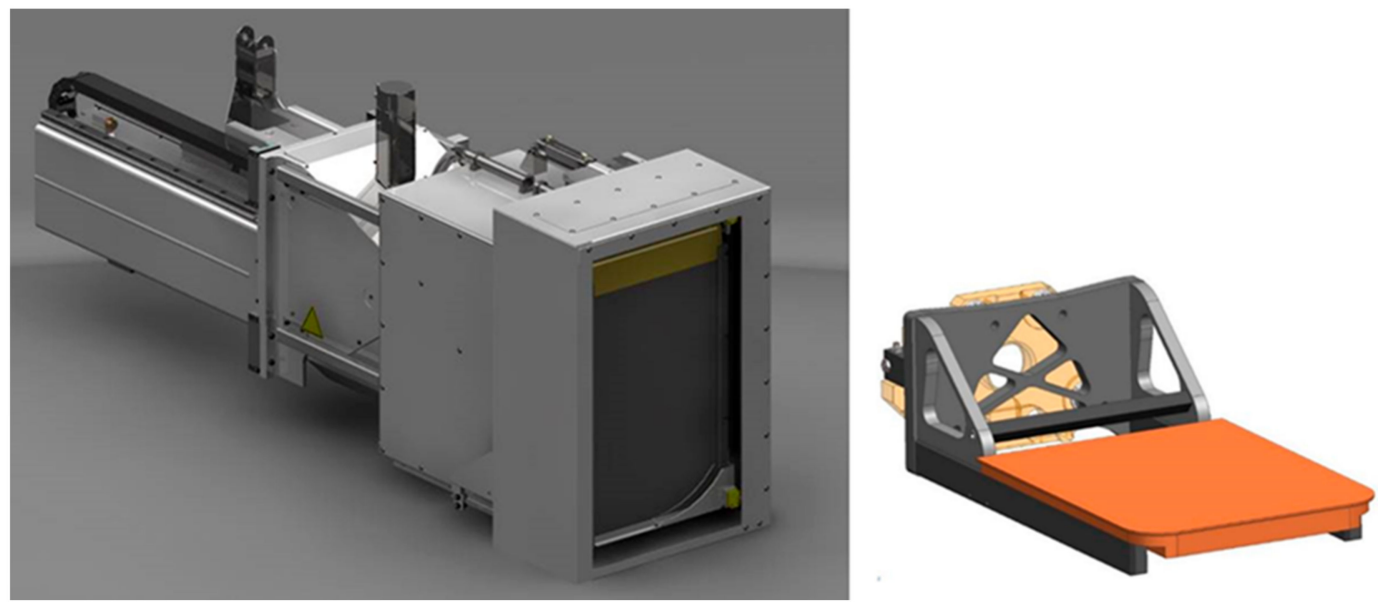

Figure 8. EROWA robot arm (based on ERD5 new axis drive concept) with designed dust box (left) and gripper with pallet (right) for HyProCell.

With the assessed requirements and dimensions, a standard curtain gate solution was used for the robot access door. The integration of this gate takes into account the necessary fitting of the dust box, with the usage of a specific collecting plate to avoid powder loss while transferring the part to the handling system. Also, control of the gate must be coordinated with the rest of the cell to automate as much as possible.

Another important modification of the ADIRA machine was the sealing element, which is an assembly of several parts adapted to the configuration of the machine worktable and EROWA system, in order to fill the unused machine volume resulting from the integration of the EROWA system with the production substrate. The sealing element, therefore, raises the table surface to the level of the production substrate, minimizing the necessary powder for creating the first processing layer. The pneumatic system required for the EROWA base plate operation, which enables the control of the pneumatic chucks, was specified by the supplier and incorporated by ADIRA. The system comprises connections for opening and closing the chucks with a pressure switch to provide feedback on the state of the chuck. To facilitate control of the chuck system, a pneumatic field bus was incorporated into the AddCreator with PROFINET connection for valve control using the system's internal communication protocol. 


\section{Key Results}

\subsection{ICT Framework and Toolbox}

AUTODESK developed and customised different software to streamline the Hybrid AM workflow in HyProCells. NetFabb ${ }^{\circledR}$ [13] and PowerShape ${ }^{\circledR}$ [14] utility were mainly used for L-PBF process in the SLM pilots and for design for additive manufacture activities (DFAM), while PowerMill ${ }^{\circledR}[15]$ was used for LMD and five-axis machining. Design and process data were made accessible to anyone, anywhere and at any time using AUTODESK's Cloud Solutions based on Fusion Team deployment. The main objective was to develop toolboxes that would enable the generation of design data and fault-free manufacturing data for the value chain. Integration of product design, modelling, technology planning, and equipment planning is necessary nowadays [16]. AUTODESK, along with other partners in the project, started with existing CAx solutions and tools for driving Additive and Subtractive Manufacturing technologies and developed different toolboxes to drive the manufacturing processes in the entire value chain. Specifically, dedicated toolboxes were generated to create fault-free manufacturing data for LBAM (including SLM and LMD) and subtractive manufacturing production machines aimed at first-time-right concept and high-throughput manufacturing.

These toolboxes were applied to both the LMD use case (HAMUEL's hybrid LMD manufacturing machine located at AUTODESK) and the SLM use case (ADIRA's TLM machine in combination with other machines located at POLY-SHAPE) covered in the project. The toolbox allowed a mix-and-match of tools to suit the needs of a wide range of manufacturing scenarios within the use cases. An example of the modelling for manufacturing toolbox framework in HyProCell is shown in Figure 9.

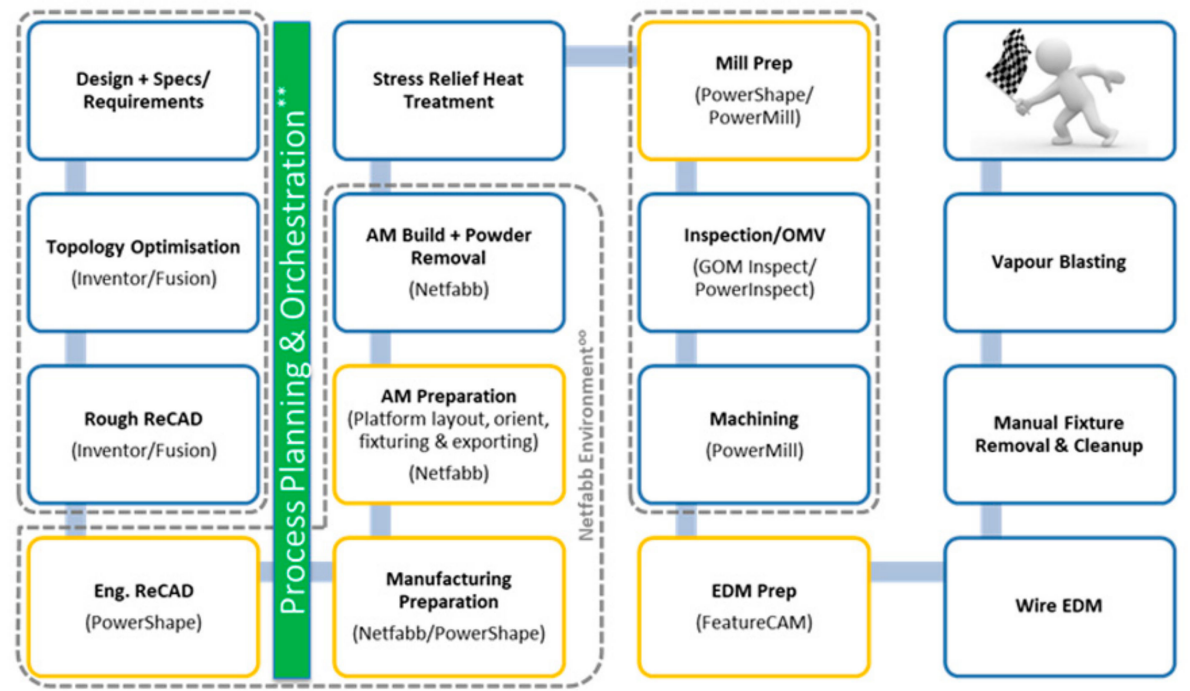

Figure 9. Modelling for AM ICT framework based on AUTODESK software and toolboxes.

Netfabb Ultimate ${ }^{\circledR}$ was used in HyProCell as the primary additive build preparation software in the SLM use cases for common preparation needs, such as setting nesting and orientation of parts, support structures, and creating the build files necessary to control the ADIRA TLM machine. PowerMill Additive ${ }^{\circledR}$ is a plugin that enables CNC programmers to create toolpaths for additive or hybrid manufacturing in the LMD use cases addressed, creating specific strategies for directed energy deposition. It utilizes PowerMill's multi-axis $\mathrm{CNC}$ capabilities to create multi-axis additive toolpaths with detailed process parameter control along every point of the toolpath. These process parameters enable fine control of the LMD operations at a toolpath point level. The first step was to create the CAD of the part (nozzle Ring shown in grey), the preform of the blade is created in step 2 with PowerShape. The manufacturing sequence for the part is: clamping of the base ring, 
alternating deposition of the blades over the base ring, their machining and final laser cladding of the top ring. The complete CAx LMD workflow is depicted in Figure 10 below.

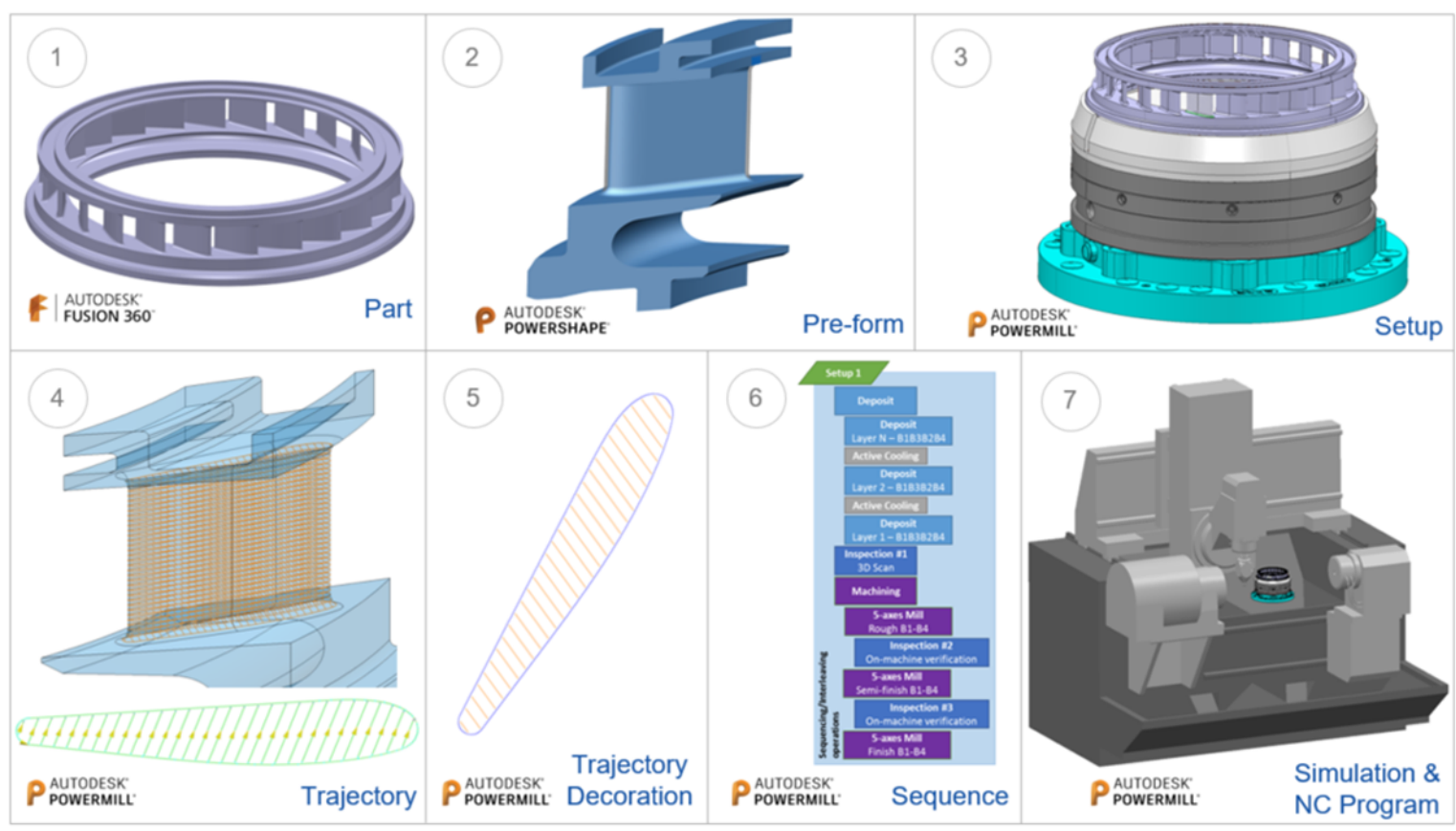

Figure 10. Complete CAx for Hybrid LMD workflow.

An underlying multi-location data hosting and cloud environment (AUTODESK Fusion Team) supports these design and manufacturing toolboxes, and was implemented and deployed within the project. AUTODESK Fusion Team is one of the primary cloudbased data hosting containers available within AUTODESK as part of the broader cloud solutions from AUTODESK. Fusion Team provides a central collaborative workspace in the cloud (hub) for process development projects.

Relevant HyProCell partners got access to Fusion Team and could view the HyProCell Hub and create their own storage hubs for collaborative work. Several methods for accessing storage hubs on multiple devices were demonstrated with the web interface developed, with Desktop Connector being the preferred access method. Desktop Connector integrates an AUTODESK data management source (or data source), the user's desktop folder, and file structure for easy file management. Since files in the data source are replicated in a connected drive, files can be managed in the data source through the connected drive, just as a user would do in any other folder on the user's computer. Changes made in the connected drive are automatically uploaded to the data source.

\subsection{MES and Data Management}

The main objective in creating a manufacturing execution system (MES) was to control the whole hybrid production cell including the knowledge discovery module, providing production data management, tracking, and automated production management.

The MES is considered the base for development of multi-sided platforms for cyber physical systems (CPS) in the digital factory trend [17] and for more flexible cyber physical production systems (CPPS). SmartFactory-KL has demonstrated in the past that harmonising these concepts and technologies to transform classic and static manufacturing automation design to flexible CPPS is possible [18]. In HyProCell, the MES was developed and validated by prototypes in the RAMEM and POLY-SHAPE pilot cells through the production of the SLM use cases. The MES offers the following functions: 
(i) Controls machines from different vendors adapted to the HyProCell architecture using unified standard commands. Different machines can be added to the cell if a suitable OPC-UA adapter can be developed.

(ii) Provides a browser-based human-machine interface (HMI) for the operator of the production cells. The operator can load and unload pallets into the cell, associate work orders to pallets, and start and stop machines manually when the MES is not in automatic mode. The operator can also download drawings in PDF format for tooling reference.

(iii) Unifies the HMI with manual stations outside the cells to track production all along the production cycle. Operators of external workstations can connect to the MES using a web browser and update the status of manual operations.

(iv) Allows the upload of measurement results and associates them to the corresponding job for later retrieval.

(v) Collects information about the state of machines as well as the start and end time of each job on each machine.

(vi) Tracks pallet loading and unloading using the RFID reader integrated in the loading station. This also allows pallet tracking outside the cell using a USB RFID reader.

(vii) Provides a remote interface for production engineers to define a work sequence for products, associating the required part programs to the work order.

(viii) Provides a remote interface for the production manager to create work orders and send them to the production schedule. Once a production manager sends an order to production, it will appear in the HMI of the cell for the operator, who will be able to load it into the cell.

(ix) Automatically downloads the part programs from a central repository and uploads them on the machines when in automatic mode.

(x) Automatically unloads the machines when a job is finished and loads the next pallet according to a schedule algorithm.

The human-machine interfaces allow operators to intuitively configure, plan, and interact with the cell. Seven main modules/tabs were developed: Cell Configuration, User management, Production Management, Cell Management, Cell Monitor, Loading Station, and Measurement Station. Figure 11 shows an example of the interface for one module.

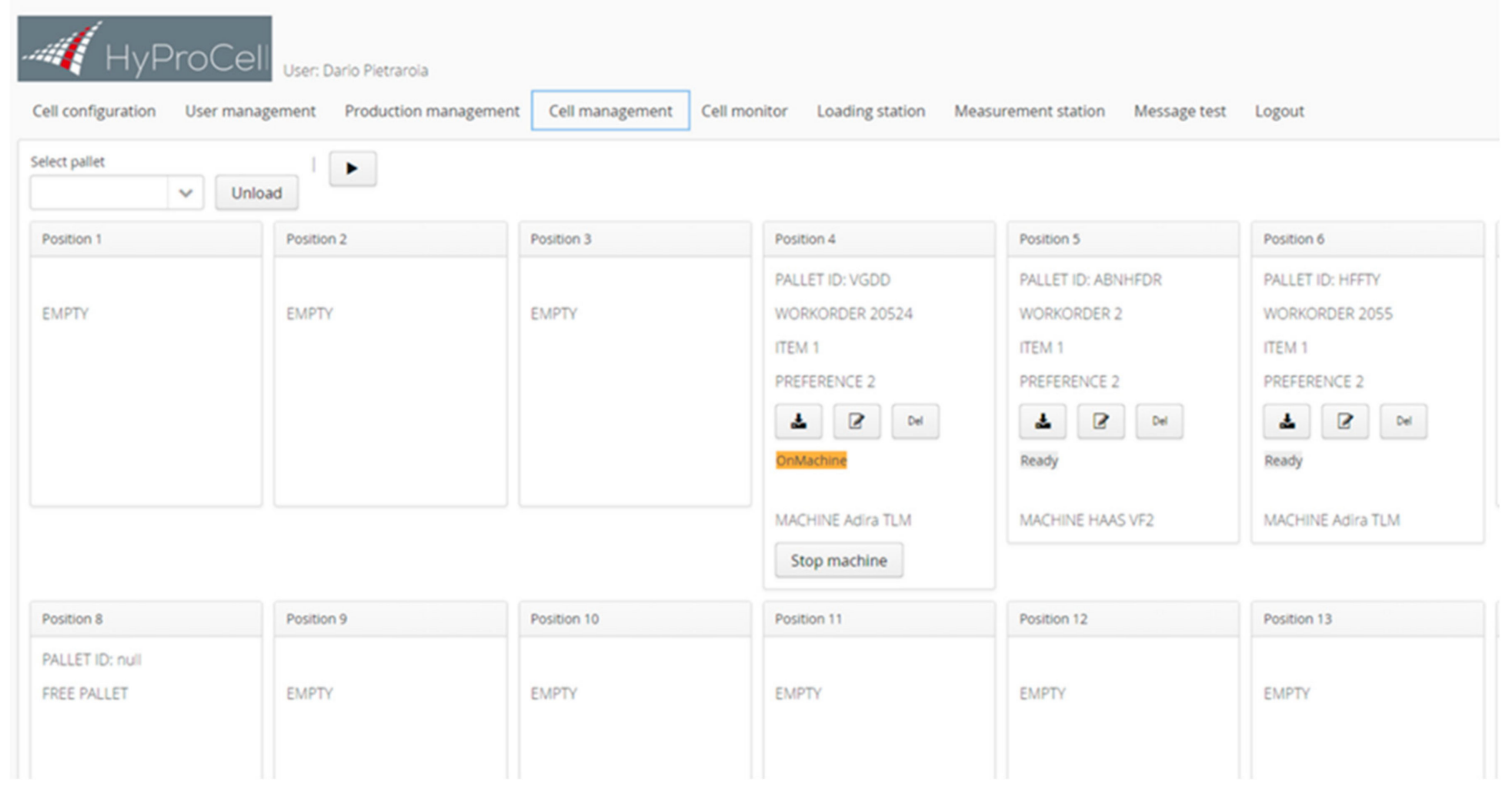

Figure 11. Screenshot capture of the Cell management interface of the MES running in the SLM Pilot Cell at Poly-Shape. 
Furthermore, LORTEK developed a method entitled splitting, clustering, graphmaking (SCG) to allow data analytics and data mining using time series processing [19] of data acquired from SLM machines, all under the umbrella of Big Data in Industry 4.0 [20]. This method is grounded on the Ward's clustering algorithm [21] and it brings two innovations: sample-making and visualisation. The first encompasses building suitable samples aimed at reaching data exploring objectives, and the second is for showing both a graph-based and a time-based view of the data. The SCG method allows for the detection of stable working states on a machine(s) in the cell. This is key for understanding the manufacturing process, while at the same time providing insights for knowledge discovery and monitoring for quality improvements. The methodology and early results were published in a scientific research paper and presented in the 20th International Conference on Intelligent Data Engineering and Automated Learning [22]. This methodology is the basis for the knowledge discovery module included in the MES.

\subsection{Hybrid AM Workflow and Pilot Facilities Implementation}

Hybrid AM has a high potential for production in smart factories of the future and in current Industry 4.0 trends [23]. Hybrid AM covers various ways of producing components with different manufacturing processes, materials, and functions, which are divided according to their requirements. The aim, for example, could be the reduction of lead time and costs, e.g., by reducing the number of machining steps required, which would see time and material cost reduced, or by merging several individual parts into one component, thereby shortening the process chains (e.g., for assembly operations) and reducing variability and scrap page rate due to increased quality [24]. Another important thing is the automatic evaluation of manufacturability and generation of adequate process plans for hybrid manufacturing [25] in order to reduce production time and time-to-market. The entire AM value chain and the processes and solutions integrated in the SLM pilot cell are shown in Figure 12, which include at least 10 stages before shipping, from design to quality control. The integration of several processes involved in the AM value chain was evaluated initially in the project proposal stage, then at the beginning of the project and deeply analysed in the first Technical Committee in 2017 after in-depth technical discussions and finding the best solutions available. Current HyProCell workflow covers six steps with the innovations proposed in the Hybrid SLM cell at POLY-SHAPE. However, the remaining four, namely, thermal treatment, separation for building plate, support removal and special finishing (if required) have not been integrated in the cells. The validation of the cells was carried out satisfactorily in December 2019, and as a result, it was possible to measure the key performance indicators of the new production workflow for four different use cases for the aerospace, industrial, turbomachinery, and energy sectors.

The SLM pilot cells were designed to operate as Hybrid AM cells. Therefore, a key goal is to be able to produce competitively and efficiently in the cell (with required accuracy and specifications) and avoid unnecessary transfers to other outside machines/processes. It is often necessary to use several manufacturing processes sequentially. The following processes/operations are not included but could be integrated in the near future:

- Heat treatment

- Separation from building plate

- Support removal

- Additional surface finishing (with an automated dry electropolishing system if required) 


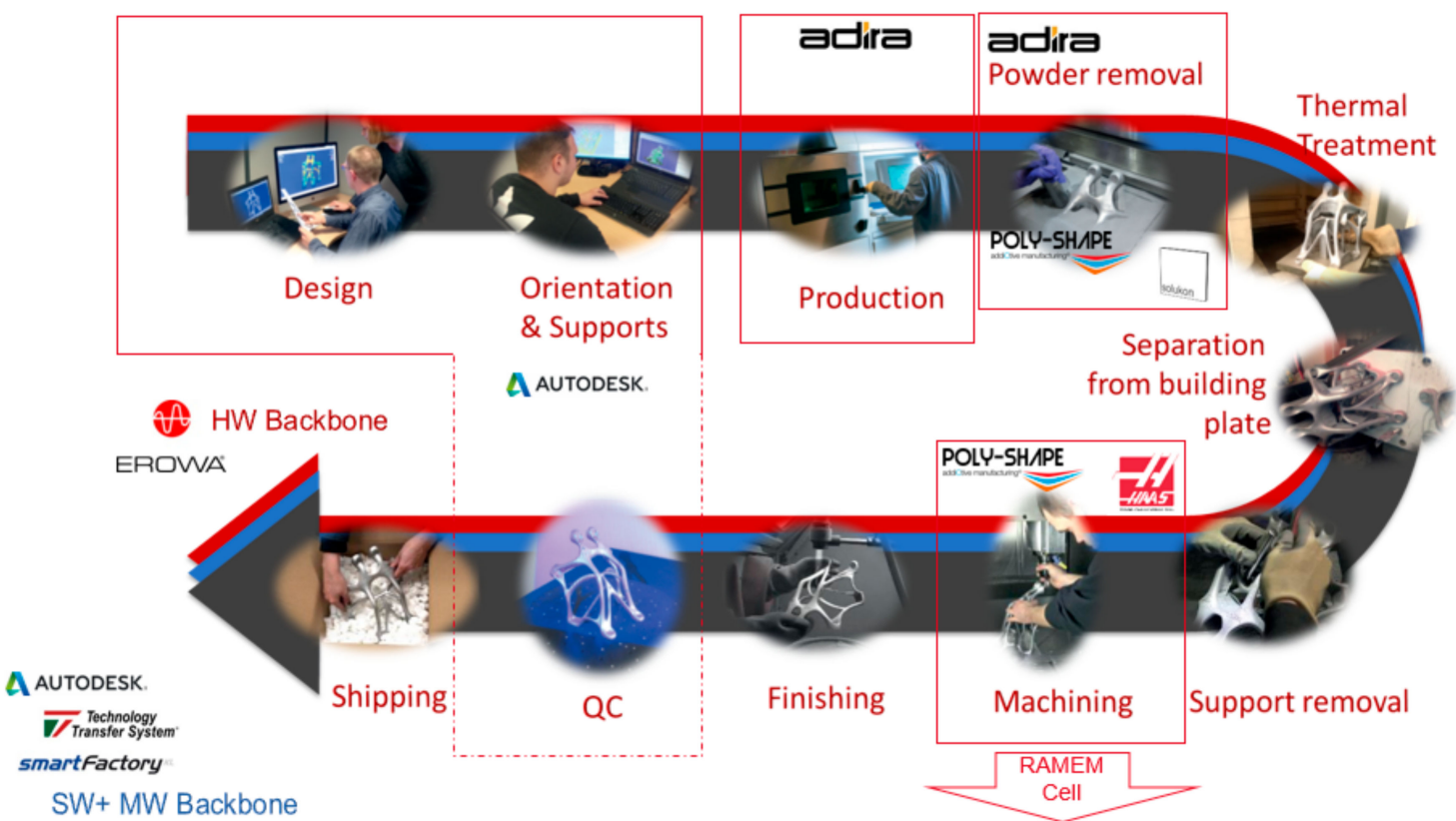

Figure 12. AM value chain and stages involved. Identification of stages and processes addressed (red Boxes) in the SLM pilot cell at POLY-SHAPE.

The following pictures in Figure 13 show the Hybrid SLM production cell at POLYSHAPE (left) and post-processing cell for machining SLM parts in RAMEM (right), and detailed features of the cells are shown in the final dissemination video of the project, also accessible through the HyProCell project webpage.
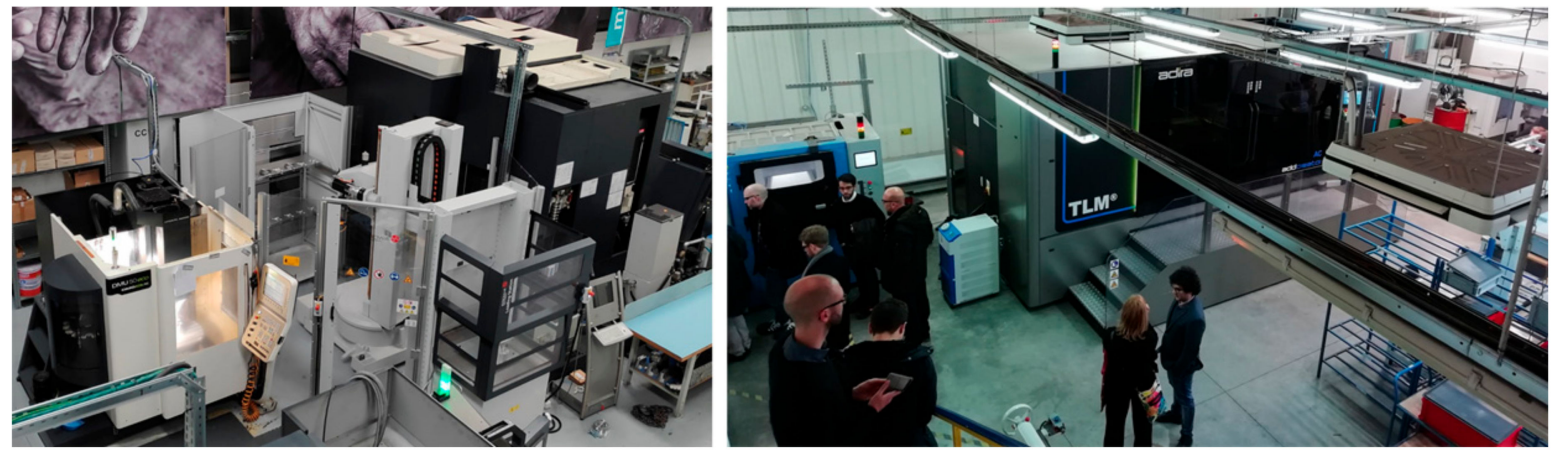

Figure 13. Final demonstrations of the Hybrid SLM production cell at POLY-SHAPE (right) and post-processing cell for machining SLM parts in RAMEM (left).

\section{Discussion}

The results of the HyProCell project apply across different market segments, and it is foreseen that laser-based deposition methods like LMD will have high demand in the industry due their potential for flexibility in tailored compositions for coatings and additive manufactured parts [26]. In terms of LPBF process to fabricate geometrically complexshaped parts (like SLM), there is a tremendous potential for improving the heat transfer efficiency of thermal management components [27] and lightweight of many components for aeronautic and aerospace applications.

It is known from the SWOT-analysis of the European photonics industry [28], conducted by the EC a few years ago, that the key strengths of the European photonics industry are the close participation of global market leaders in several core industrial segments and its established links with application industries. HyProCell built on these strengths by involving end-user industries in the project. Indeed, to ensure quick market uptake 
of innovation, HyProCell involved end users ABB turbo, RAMEM and POLY-SHAPE, who provided detailed requirements and validated the suitability of produced parts. A summary of the values obtained for each key performance indicator (KPI) against the six main objectives in HyProCell is compiled in Table 1.

Table 1. Main outputs of HyProCell for each KPI related to the main objectives defined in the project.

\begin{tabular}{|c|c|c|c|}
\hline HyProCell Objectives & KPI & $\begin{array}{l}\text { Measured } \\
\text { (Value or Feature) }\end{array}$ & Comments \\
\hline $\begin{array}{l}\text { 1. More flexible and } \\
\text { reconfigurable LBAM focused } \\
\text { production cells }\end{array}$ & $\begin{array}{l}\text { Capacity of the cells to be } \\
\text { reconfigurable }\end{array}$ & $\begin{array}{l}\text { Yes, modular architecture } \\
\text { developed, validated, and } \\
\text { demonstrated }\end{array}$ & $\begin{array}{l}\text { Guaranteed flexibility for quick } \\
\text { cell reconfiguration }\end{array}$ \\
\hline $\begin{array}{l}\text { 2. Reduce the time required to } \\
\text { develop manufacturing } \\
\text { procedures for new products }\end{array}$ & Time to develop new products & $\begin{array}{l}\text { With CAx toolboxes deployed and } \\
\text { with LBAM machines modified and } \\
\text { tested for both LMD and SLM use } \\
\text { cases, a reduction of } \\
\text { time-to-develop new product from } \\
\text { weeks to days was observed }\end{array}$ & $\begin{array}{l}\text { Different toolboxes developed to } \\
\text { drive the manufacturing } \\
\text { processes (hybrid AM workflow) } \\
\text { in the entire value chain with the } \\
\text { HyProCell approach }\end{array}$ \\
\hline $\begin{array}{l}\text { 3. Decrease downtime by } 50 \% \\
\text { when SLM is the process involved } \\
\text { in part production }\end{array}$ & $\begin{array}{l}\text { Downtime for production of } \\
\text { Hybrid SLM parts }\end{array}$ & $\begin{array}{l}\text { Downtime in HyProCell Hybrid } \\
\text { SLM cell: } \\
\downarrow 110 \text { min }(35 \%)\end{array}$ & $\begin{array}{l}\text { Best results achieved in one of the } \\
\text { use cases. Comparisons against } \\
\text { conventional AM route }\end{array}$ \\
\hline $\begin{array}{l}\text { 4. Increase the incomes coming } \\
\text { from functional parts provided to } \\
\text { industry from the current } 10 \% \\
\text { to }>50 \%\end{array}$ & Production productivity & $\begin{array}{l}\text { Full use of AM machines and robots } \\
\text { would lead to a productivity } \\
\text { increase in Hybrid SLM. However, } \\
\text { more rigorous analysis covering the } \\
\text { entire value chain with HyProCell } \\
\text { workflow is required to evaluate } \\
\text { incomes from functional parts }\end{array}$ & $\begin{array}{l}\text { 8-10 SLM machines are required } \\
\text { to take full advantage of the } \\
\text { HyProCell approach in the } \\
\text { near future }\end{array}$ \\
\hline $\begin{array}{l}\text { 5. Extend the type of components } \\
\text { manufactured by LBAM based on } \\
\text { the new automated hybrid } \\
\text { production workflow }\end{array}$ & $\begin{array}{l}\text { Capacity to manufacture } \\
\text { different part geometries and } \\
\text { sizes for different sectors }\end{array}$ & $\begin{array}{l}\text { Yes, the capacity to produce six (6) } \\
\text { different parts from three ( } 3 \text { ) sectors } \\
\text { was demonstrated: four (4) in } \\
\text { Hybrid SLM and two (2) in Hybrid } \\
\text { LMD pilot cell }\end{array}$ & $\begin{array}{l}\text { New automated Hybrid AM } \\
\text { production workflow developed } \\
\text { in HyProCell can be extrapolated } \\
\text { to a wide range of components } \\
\text { manufactured by LBAM }\end{array}$ \\
\hline $\begin{array}{l}\text { 6. Improve data management, } \\
\text { allowing a better monitoring of } \\
\text { process data and cell performance }\end{array}$ & $\begin{array}{l}\text { Improved production cell } \\
\text { performance after optimisation } \\
\text { through data mining }\end{array}$ & $\begin{array}{l}\text { Solutions based on algorithms for } \\
\text { data analytics were developed, but } \\
\text { more data mining during TLM } \\
\text { machine life/operation is needed to } \\
\text { foresee improvements in production } \\
\text { time and part quality }\end{array}$ & $\begin{array}{l}\text { Basis for knowledge discovery } \\
\text { module were established and } \\
\text { tested [22] }\end{array}$ \\
\hline
\end{tabular}

\section{Conclusions}

Three manufacturing pilot lines were created in the framework of HyProCell. The pilot lines were intended to give European industry access to proven Hybrid LBAM solutions and manufacturing, allowing the opportunity to test and validate ideas and new products prior to market entry. The pilot lines aim to increase the productivity of machine and production line manufacturers and their clients (OEMs), especially during design and ramp-up phases, as the project deals with the integration of machines and production lines. The main conclusions and lessons learnt are grouped in three categories: General, SLM pilot, and LMD pilot.

In general:

(i) Modularity and reconfigurable hybrid AM production cell is a reality; however, such solutions are useful for certain business cases, not as a general solution for all cases.

(ii) The main limitation for hybrid AM industrial production of large and heavy parts is the additive manufacturing process and the intervention of operators. With the ADIRA machine and its modifications to operate in HyProCell, the build size restrictions and operability are significantly tackled. The solutions developed for transfer and handling of these parts were shown to be robust, efficient, and accurate. In addition, the MES developed in HyProCell opens new possibilities for automating the zeroing of AM machines and getting a stock of available build plates. The missing bricks to be included in future versions of the MES are: ability to manage substrates 
instead of pallets; automated probing cycles to establish thickness and flatness of substrate; in-line data analysis of build plate geometry; and adequate positioning of parts on substrates in accordance with production planning and risks of distortion.

(iii) The major challenge of integrating $\mathrm{AM}$ and subtractive machining in the current hybrid workflow is the need for a "hybrid process-planning" protocol for postprocessing of AM parts that accounts for the varying processing nature of AM (material shrinkage, layer thickness, orientation, anisotropy, etc.), machining (tool design, machining allowance, etc.), and part-specific attributes (critical features and tolerance requirements).

SLM pilot cell:

(i) Integration of real machines in a hybrid AM cell is an effort which should receive further development attention, especially when such cells use legacy machines. The standardisation of OPC-UA and the use of the standard is still uncommon in both additive and subtractive machine tools. Since the implementation of all or some elements of the OPC-UA standard is left to the discretion of the manufacturers of PLCs, best practices, tutorials, and open "code snippets" are needed to boost their use. A platform for different PLCs from different manufacturers, where this "integrationknowledge" is stored, will facilitate the development of OPC-UA interfaces so that PLC programmers might gain more control, freedom, and speed in development. To make it easier for them, the tools to create this OPC-UA models must also be easy to operate and understand.

(ii) A fast feedback loop between different system designers (monitoring tool, machine manufacturer, control device programmers, information model, MES, etc.) is crucial for a good product. Starting with an appropriate project platform can help a lot for the future.

(iii) It is advantageous to use a constant/fixed part coordinate system, such as the pallet system, to seamlessly switch between additive, subtractive, and other operations. It is necessary to guarantee part accuracy and repeatability. Methods to define/create a part coordinate system in the hybrid AM workflow need to be considered from the beginning of the cell conception. Distortions during the AM process can cause differences of positioning compared to theoretical expectations, and this needs to be corrected by testing measurements in the machining machine.

(iv) Reaching the best level of automation and integration in the SLM pilot cell would result in a significant reduction in downtime. This was demonstrated for each defined batch production scenario.

LMD pilot cell:

(i) The function of a combined machine for additive and subtractive machining is a highly focused one with a clear need. It must be clear that the required process relies on the functions available within such a machine type. Such functional combination is required for repair. Repair has a strong focus on adaptive machining as well, which makes measurement capabilities in the machine essential. The currently available measurement solutions in machine tools such as touch probes and laser line scanning sensors are accurate but slow; therefore, compromises between timeliness and accuracy must be made.

(ii) The machine operator on the shop floor must be properly supported. Machine operators are usually focused on a single process. The combination of additive, adaptive, and subtractive machining with all their relations is very difficult for an operator to handle. The process needs—and this is essential—complete adaptation of the additive and subtractive tool paths for each individual part. Automated communication and exchange of data between the machine and connected CAM system ensures a fast and reliable process.

(iii) In hybrid LMD workflows, the downtime associated with constant tool changes caused by switching between deposition and machining is a non-value adding step. 
It is preferable to carry out as much material deposition as possible before moving on to the machining phases. Software tools are needed in the future to optimise this sequencing.

(iv) Creating net shape of LMD structures is currently not possible with today's technology. Near net shape of LMD structures is possible, as demonstrated with the nozzle ring and turbine blades demonstrators. Hybrid manufacturing allows shapes to be simultaneously produced and finished, which would otherwise be difficult to access with a milling tool, as was the case with turbine blades.

(v) Multi-layer LMD process (not just cladding for coating, but build-up of a 3D structure) is possible and has been demonstrated. Production of slight overhangs with LMD is possible, and if deposition speeds and powder capture efficiency can be increased and made repeatable, more positive business cases can be reached.

Author Contributions: J.C.P.: Conceptualization, Methodology and Writing-Original draft preparation; R.M.: Writing-Original draft preparation; C.T.: Redaction of Pilot facilities setup section; A.H. and T.W.: Redaction of Section 2.2 relative to the modular architecture, automation, and pallet handling system and their analysis. K.H.: redaction of Section 3.1 (ICT framework and toolbox developed) and also in charge of the reviewing and editing of the paper. All authors have read and agreed to the published version of the manuscript.

Funding: This research was funded by the European Union's Horizon 2020 research and innovation programme under Grant Agreement No. 723538 in Call for Proposal H2020-FOF-2016. The project was framed in the initiative for advanced manufacturing research and innovation of the Photonics and Factories of the Future PPP.

Institutional Review Board Statement: Not applicable.

Informed Consent Statement: Not applicable.

Data Availability Statement: The raw/processed data required to reproduce these findings cannot be shared at this time due to technical or time limitations.

Acknowledgments: The authors would like to thank the European Commission for funding the HyProCell project in the Factories of the Future $(\mathrm{FoF})$ programme, a public-private partnership (PPP) for advanced manufacturing research and innovation initiative.

Conflicts of Interest: The authors declare no conflict of interest.

\section{References}

1. Schmidt, M.; Merklein, M.; Bourell, D.; Dimitrov, D.; Hausotte, T.; Wegener, K.; Overmeyer, L.; Vollertsen, F.; Levy, G.N. Laser based additive manufacturing in industry and academia. CIRP Ann. 2017, 66, 561-583. [CrossRef]

2. Gisario, A.; Kazarian, M.; Martina, F.; Mehrpouya, M. Metal additive manufacturing in the commercial aviation industry: A review. J. Manuf. Syst. 2019, 53, 124-149. [CrossRef]

3. Stavropoulos, P.; Foteinopoulos, P.; Papacharalampopoulos, A.; Bikas, H. Addressing the challenges for the industrial application of additive manufacturing: Towards a hybrid solution. Int. J. Light. Mater. Manuf. 2018, 1, 157-168. [CrossRef]

4. Campbell, I.; Diegel, O.; Kowen, J.; Wohlers, T. Wohlers Report 2018: 3D Printing and Additive Manufacturing State of the Industry: Annual Worldwide Progress Report; Wohlers Associates: Fort Collins, CO, USA, 2018.

5. Chong, L.; Ramakrishna, S.; Singh, S. A review of digital manufacturing-based hybrid additive manufacturing processes. Int. J. Adv. Manuf. Technol. 2018, 95, 2281-2300. [CrossRef]

6. Dröder, K.; Heyn, J.K.; Gerbers, R.; Wonnenberg, B.; Dietrich, F. Partial Additive Manufacturing: Experiments and Prospects with Regard to Large Series Production. Procedia CIRP 2016, 55, 122-127. [CrossRef]

7. Reichler, A.-K.; Gabriel, F.; Timmann, F.; Steil, J.; Dröder, K. An architecture for AutomationML-based constraint modelling and orchestration of Incremental Manufacturing. Procedia CIRP 2019, 86, 173-178. [CrossRef]

8. Torres-Carrillo, S.; Siller, H.R.; Vila, C.; López, C.; Rodríguez, C.A. Environmental analysis of selective laser melting in the manufacturing of aeronautical turbine blades. J. Clean. Prod. 2020, 246, 119068. [CrossRef]

9. Ramakrishnan, A.; Dinda, G.P. Direct laser metal deposition of Inconel 738. Mater. Sci. Eng. A 2019, 740-741, 1-13. [CrossRef]

10. Zakoldaev, D.A.; Shukalov, A.V.; Zharinov, I.O.; Novikov, A.S. Modular architecture of cyber-physical production for Industry 4.0. J. Phys. Conf. Ser. 2019, 1399, 44010. [CrossRef] 
11. Pahlevannejad, P.; Herget, A.; Moreno, R.; Hennecke, A.; Ruskowski, M. Implementation and Testing of a Modular System Architecture for Generic Hybrid Production Cells in an Industrial Environment. In Proceedings of the IECON 2019 45th Annual Conference of the IEEE Industrial Electronics Society, Lisbon, Portugal, 14-17 October 2019; Volume 1, pp. 4229-4234.

12. SmartFactory-KL HyProCell Software System Architecture. Available online: https:/ / youtu.be/a1RXyIEj_IE (accessed on 23 June 2020).

13. Autodesk Netfabb 3D Printing Software. Available online: https://www.autodesk.com/products/netfabb/features (accessed on 24 June 2020).

14. Autodesk PowerShape CAD Software. Available online: https://www.autodesk.es/products / powershape/ (accessed on 24 June 2020).

15. Autodesk PowerMill Additive Plugin. Available online: https://knowledge.autodesk.com/support/powermill/getting-started/ caas/CloudHelp/cloudhelp/2019/ENU / PWRM-Additive/files/GUID-5B32F5CB-8DDC-475C-9450-07285615BF9E-htm.html (accessed on 24 June 2020).

16. Jacob, A.; Steimer, S.; Stricker, N.; Häfner, B.; Lanza, G. Integrating product function design, production technology optimization and process equipment planning on the example of hybrid additive manufacturing. Procedia CIRP 2019, 86, 222-227. [CrossRef]

17. Landolfi, G.; Barni, A.; Menato, S.; Cavadini, F.A.; Rovere, D.; Dal Maso, G. Design of a multi-sided platform supporting CPS deployment in the automation market. In Proceedings of the 2018 IEEE Industrial Cyber-Physical Systems (ICPS), St. Petersburg, Russia, 15-18 May 2018; pp. 684-689.

18. Hennecke, A.; Ruskowski, M. Design of a flexible robot cell demonstrator based on CPPS concepts and technologies. In Proceedings of the 2018 IEEE Industrial Cyber-Physical Systems (ICPS), St. Petersburg, Russia, 15-18 May 2018 ; pp. 534-539.

19. Aghabozorgi, S.; Seyed Shirkhorshidi, A.; Ying Wah, T. Time-series clustering-A decade review. Inf. Syst. 2015, 53, 16-38. [CrossRef]

20. Gokalp, M.O.; Kayabay, K.; Akyol, M.A.; Eren, P.E.; Koçyiğit, A. Big Data for Industry 4.0: A Conceptual Framework. In Proceedings of the 2016 International Conference on Computational Science and Computational Intelligence (CSCI), Las Vegas, NV, USA, 15-17 December 2016; pp. 431-434.

21. Murtagh, F.; Legendre, P. Ward's Hierarchical Agglomerative Clustering Method: Which Algorithms Implement Ward's Criterion? J. Classif. 2014, 31, 274-295. [CrossRef]

22. Moreno, R.; Pereira, J.C.; López, A.; Mohammed, A.; Pahlevannejad, P. Time Series Display for Knowledge Discovery on Selective Laser Melting Machines. In Intelligent Data Engineering and Automated Learning-IDEAL 2019; Yin, H., Camacho, D., Tino, P., Tallón-Ballesteros, A.J., Menezes, R., Allmendinger, R., Eds.; Springer International Publishing: Cham, Switzerland, 2019; pp. 280-290.

23. Mehrpouya, M.; Dehghanghadikolaei, A.; Fotovvati, B.; Vosooghnia, A.; Emamian, S.S.; Gisario, A. The potential of additive manufacturing in the smart factory industrial 4.0: A review. Appl. Sci. 2019, 9, 3865. [CrossRef]

24. Häfele, T.; Schneberger, J.-H.; Kaspar, J.; Vielhaber, M.; Griebsch, J. Hybrid Additive Manufacturing-Process Chain Correlations and Impacts. Procedia CIRP 2019, 84, 328-334. [CrossRef]

25. Behandish, M.; Nelaturi, S.; de Kleer, J. Automated process planning for hybrid manufacturing. Comput. Des. 2018, 102, 115-127. [CrossRef]

26. Fotovvati, B.; Dehghanghadikolaei, A.; Namdari, N. Laser-Assisted coating techniques and surface modifications: A short review. Part. Sci. Technol. 2020, 1-10. [CrossRef]

27. Jadhav, S.D.; Dhekne, P.P.; Dadbakhsh, S.; Kruth, J.-P.; Van Humbeeck, J.; Vanmeensel, K. Surface Modified Copper Alloy Powder for Reliable Laser-based Additive Manufacturing. Addit. Manuf. 2020, 35, 101418. [CrossRef]

28. European Technology Platform Photonics21. Annual Review: Photonics21 Strategy Implementation 2016. 2017. Available online: https: / / ec.europa.eu/research/participants / documents / downloadPublic?documentIds=080166e5b1efae61\&appId= PPGMS (accessed on 5 January 2021). 